\title{
Interaction between Ideological and Political Education and Emotions of College Students Based on Brain Neuroscience
}

\author{
Yang Zhang ${ }^{1}$ \\ Chengdu University of Technology
}

\author{
Jiguang $\mathrm{Hou}^{2}$ \\ Second People's Hospital of Tibet Autonomous Region
}

\begin{abstract}
To study the interaction between ideological and political education and emotions of college students, this paper, based on literature analysis, EEG experimentation and induction summarization, briefly analyzed the concepts of ideological and political education acceptance and emotion, and their relationship. On this basis, the brain science experiment method and self-made pictures were introduced to induce the emotions of the subjects, and the physiological indicators and EEG data when they viewed the pictures were recorded. Finally, the experimental data were analyzed from the subjective emotion experience, autonomic nervous response and EEG analysis. Results have shown that the subjects who received ideological and political education differed from the ones who did not receive ideological and political education in the emotional experience. The subjects who received ideological and political education show more positive emotional experience that in turn enhances their acceptance of ideological and political education activities.
\end{abstract}

\section{Keywords}

Ideological and Political Education • Emotional Interaction • Cerebral Neuroscience

${ }^{1}$ Correspondence to: Yang Zhang (A.P.), Chengdu University of Technology, Chengdu 610059, China. Email: 26416718@qq.com

${ }^{2}$ Second People's Hospital of Tibet Autonomous Region, Lhasa 850000, China. Email: neuromonkey@qq.com

Citation: Zhang, Y., Hou, J. G. (2018). Research on the Interaction between Ideological and Political Education and Emotions of College Students Based on Brain Neuroscience. Educational Sciences: Theory \& Practice, 18(5), 1296-1305. http://dx.doi.org/10.12738/estp.2018.5.028 
The ideological and political education is to guide people to form correct ideological behaviours (Gagen, 2015). The success or failure of ideological and political education is directly related to the construction of spiritual civilization in China and the country's future and destiny. Despite its importance, the ideological and political education on university students are now still in lack. Many students refuse or pretend to accept the ideological and political education. Therefore, it is a problem to be improved urgently.

Studies have shown that the process of acceptance to education is closely related to emotions that can influence the choice of the subject's perception of ideological and political education, maintaining a stable attention to ideological and political education, and affect thinking activities and knowledge in the process of acceptance (Nadeau et al., 1995). Emotion is a rapidly changing psychological and physiological phenomenon (Francisca Pérez C et al, 2018; Seyong J et al, 2017). The advanced development of brain neuroscience imaging technology enables people to observe the brain activity of participants in cognitive tasks by the non-invasive brain imaging technology. Scholars have studied on the main brain regions for emotion processing, the relationship between different brain regions and different dimensions of emotional stimulus processing, and the relationship between different brain waves and emotional processing (Zellner, 1998), with corresponding achievements obtained.

At present, researches on the relationship between ideological and political education and emotions are mainly conducted by measurement, surveys, and neuroimaging (Panksepp, 1992). They are limited to the specific brain regions that are activated in ideological and political education, but do not involve emotions and physical activities, or further study on the brain's cognitive processing mechanism (Rustichini, 2005).

Based on the above analysis, by referring to relevant domestic and foreign references, this paper introduced the brain neuroscience experiment to study the interactive relationship between ideological and political education and emotions of college students. During the experiment, the emotions, various physiological indicators, and EEG data of the subjects induced by pictures they saw were recorded and analyzed. Finally, the interaction between ideological and political education and emotions were analyzed from the aspects of subjective emotion experience, autonomic nervous response, and EEG (Pekrun, 2006). It has been concluded that the subjects who received ideological and political education and those who did not receive ideological and political education are different in their emotional experience. Subjects who received ideological and political education have more positive emotional experience, and positive emotional experience in turn help subjects to accept ideological and political education, which provides reference for the improvement of the effectiveness of college students' ideological and political education.

\section{Relevant Theories}

\section{Ideological and Political Education Acceptance}

Acceptance is an identification behavior of people, which can be defined as active and conscious admission of people or things based on affective commitment (Schutz and DeCuil, 2002). Therefore, the acceptance of ideological and political education can be understood as personal absorption of the ideology that finally guides practice based on full understanding of the and meaning, and affective commitment (Liew, 2012). The 
acceptance of ideological and political education is a gradual internal-to-external repetitive and lifelong process, and presents the unity of theoretical acceptance and affective commitment. Studies have shown (Zembylas, 2010) that emotions can influence the choice of the subjects' perception of ideological and political education, the stable attention to the ideological and political education, thinking activities, and memory of knowledge during the process of acceptance.

\section{Related Researched on Emotions}

Emotion (Trigwell, 2012) is a high-level function of the human brain. It is a psychological process that occurs after objective things satisfy people's needs, including three aspects of physiological mechanism, subjective experience, and external performance. It can affect individual learning, memory, and decision making. Emotions reflect the adaptive mode that people adopt to the changing environment. The basic emotional theory and dimension theory (Hinton et al., 2010) are the two main existing emotional assessment standards. And the dimension theory is widely used and contains two-dimensional, three-dimensional and fourdimensional theories. Some researchers proposed (Goswami, 2006) two-factor structure of emotions, positive emotions or negative emotions, depending on the different ways of rotation in the factor analysis. Also, it is known as Happy - Unpleasant and Arousal, Figure 1 shows the structure of the emotional experience.

With the brain imaging technology, some researchers have found the brain has different systems for positive and negative emotions, and different dimensions of emotional stimulus processing correspond to different prefrontal cortical regions (Kashihara, 2014; Yaacoub et al., 2016; Gerard et al., 2016). Additionally, some studies have found that $\alpha, \beta$, and $\theta$ waves are all related to the processing of positive and negative emotions (Cabello et al., 2014).

\begin{tabular}{|c|c|c|c|c|}
\hline \multirow{5}{*}{ Unpleasan } & & High NA & \multirow{5}{*}{$\begin{array}{c}\text { Shocked } \\
\text { Surprising } \\
\text { Awakened }\end{array}$} & \multirow[b]{4}{*}{ Strong intake } \\
\hline & $\begin{array}{l}\text { sorrowful } \\
\text { Gritty }\end{array}$ & \multirow{3}{*}{$\begin{array}{l}\text { Painfully } \\
\text { Scared } \\
\text { Nervous }\end{array}$} & & \\
\hline & Hesitantly & & & \\
\hline & \multirow{2}{*}{$\begin{array}{l}\text { Sad } \\
\text { Lonely }\end{array}$} & & & \\
\hline & & Hostile & & \\
\hline \multirow{4}{*}{ Low PA } & Drowsy & & \multirow{4}{*}{$\begin{array}{l}\text { Excited } \\
\text { Proactive } \\
\text { Elated } \\
\text { Passionate } \\
\text { Strong }\end{array}$} & \\
\hline & Monotonous & & & \\
\hline & Slow & & & High PA \\
\hline & Embarrassed & & & \\
\hline \multirow{5}{*}{$\begin{array}{c}\text { Low } \\
\text { involvement }\end{array}$} & Peaceful & Quiet & \multirow{5}{*}{$\begin{array}{c}\text { Fulfilled } \\
\text { Friendly } \\
\text { Enthusiastic } \\
\text { Satisfied }\end{array}$} & \\
\hline & Silent & Calm & & \\
\hline & Stationary & Relaxed & & Нарру \\
\hline & & Peaceful & & \\
\hline & & Low NA & & \\
\hline
\end{tabular}

Figure 1. The structure of emotional experience. 


\section{Research on the Interaction between Ideological and Political Education and Emotions of College Students Based on Brain Neuroscience}

\section{Research Methods}

In order to explore the ideological and political education experience from different dimensions of emotions, 18 undergraduates were selected. Among them, nine were sophomores who had received ideological and political education, and nine were freshmen who had not yet received ideological and political education. Valence and arousal were taken as the subject's intra-emotional variables, and whether to accept ideological and political education as the inter-subject variables. The experimental materials were four self-made pictures, namely natural pictures with natural description or ideological and political education description and ideological and political education pictures with natural description or ideological and political education description, respectively. Figure 2 is a natural picture with natural description.

In the experiment, the subject was wearing a 16-lead electrode cap, as shown in Figure 3, and six physiological data of the subject's heart rate, skin temperature, and respiratory rate were measured and recorded through a multi-lead physiological device.

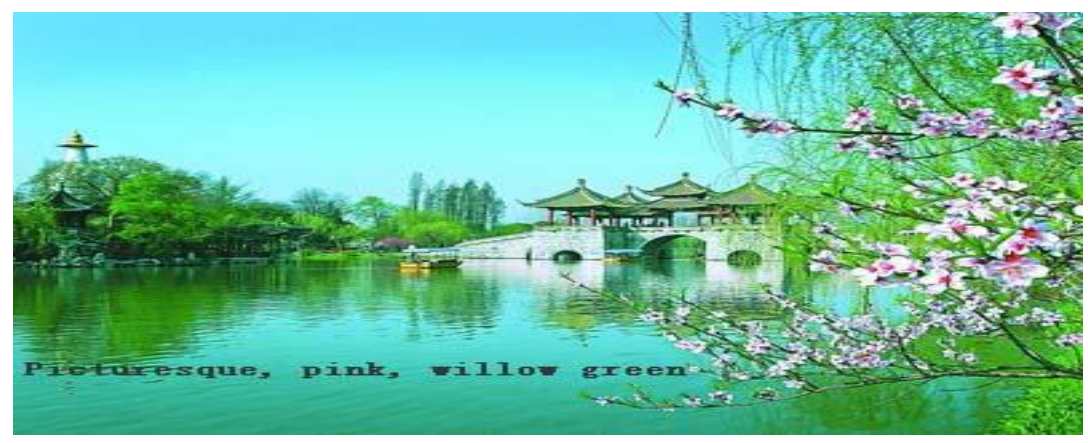

Figure 2. Natural picture with natural description.

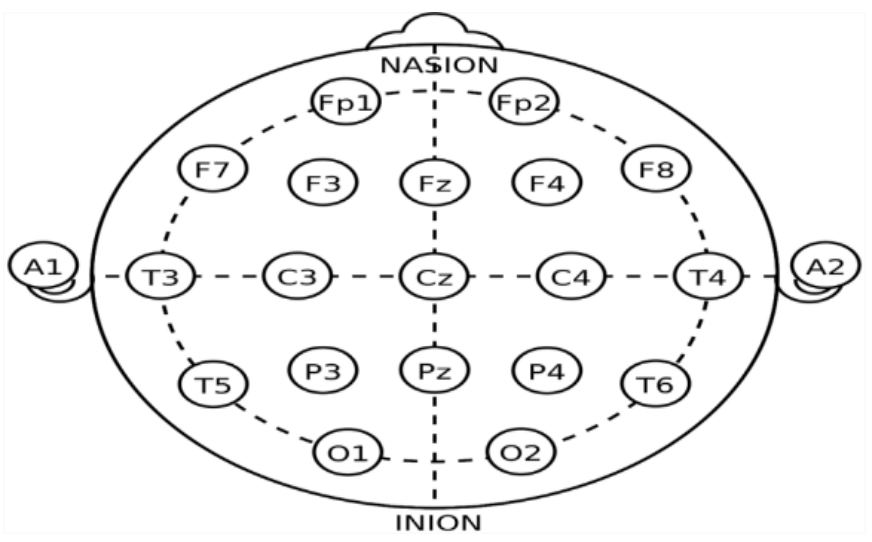

Figure 3. Electrode recording point scalp distribution map. 
At the beginning of the experiment, the subjects had a test of emotions, which required them to choose emotional words representing their current state from given words on the screen. Table 1 shows the traditional emotional words and survey-based adjectives in the five-point scale. After $3000 \mathrm{~ms}$, a set of images were presented, and subjects could have a rest for $5000 \mathrm{~ms}$ after they saw the pictures. Then subjects chose to the words that can describe their feelings on those pictures as soon as possible from randomly presented emotional words. After each set of pictures, the subjects took at least three minutes of rest to perform the next round of picture tests. The specific flow is shown in Figure 4, and Figure 5 shows the subjects who are performing experiments.

Table 1

\begin{tabular}{|c|c|c|c|c|c|c|c|c|}
\hline $\begin{array}{l}\text { Traditional } \\
\text { emotional } \\
\text { adjectives }\end{array}$ & Happy & Calm & Surprise & Fear & Sad & Disgust & Interest & Anger \\
\hline $\begin{array}{l}\text { Emotional } \\
\text { adjectives } \\
\text { obtained from } \\
\text { the survey }\end{array}$ & Peace & Joy & Comfort & Hope & Thanksgiving & Wonderful & Sadness & Sad \\
\hline
\end{tabular}

At the end of the experiment, the six physiological data obtained from the records were converted into numbers for variance analysis by Spss10.0. The original EEG data was filtered and Fourier transformed, and then imported into Spss10.0 for variance analysis.

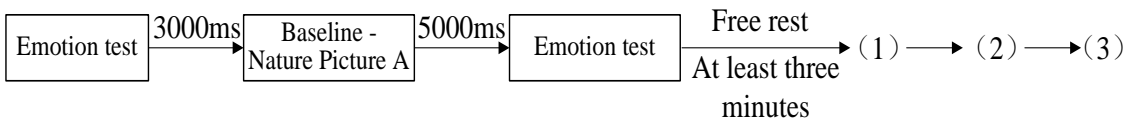

Note: (1), (2), (3) represent the other three groups of experimental stimuli, and the process is the same as the previous baseline stimuli.

Figure 4. Experimental flowchart.

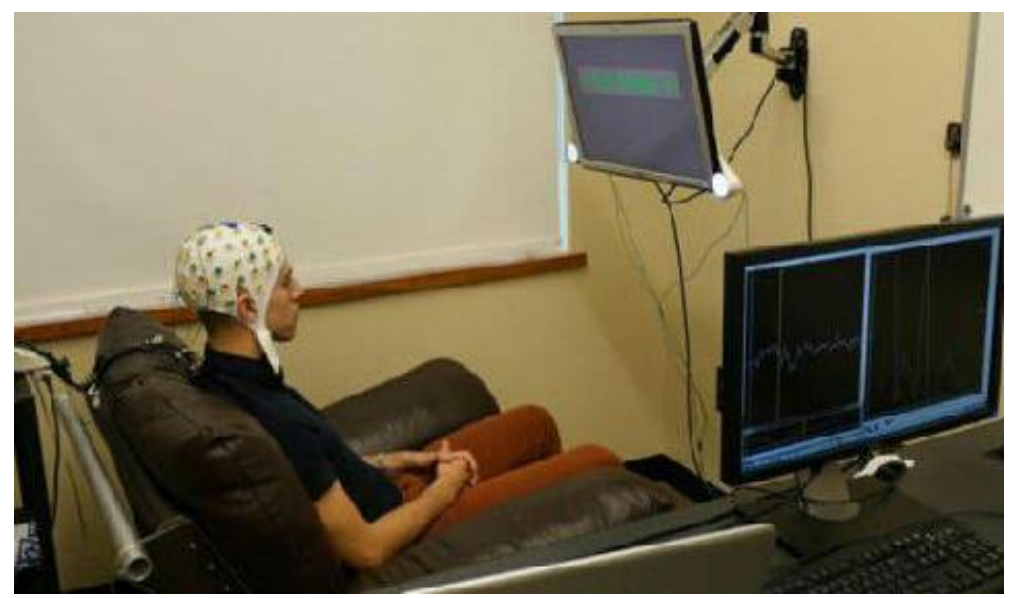

Figure 5. Subjects performing tests. 
Table 2

Subjective Experience Change Table When Two Groups of Subjects Watch Different Pictures

\begin{tabular}{|c|c|c|c|c|c|c|c|c|}
\hline \multirow{2}{*}{ Experience project } & \multicolumn{2}{|c|}{ Baseline $(\mathrm{M} \pm \mathrm{SD})$} & \multicolumn{2}{|c|}{ A condition $(\mathrm{M} \pm \mathrm{SD})$} & \multicolumn{2}{|c|}{$\mathrm{B}$ condition $(\mathrm{M} \pm \mathrm{SD})$} & \multicolumn{2}{|c|}{$\mathrm{C}$ condition $(\mathrm{M} \pm \mathrm{SD})$} \\
\hline & Accept & Not accepted & Accept & Not accepted & Acept & Not accepted & Accept & Not accepted \\
\hline Happy & $.40 \pm .51$ & $.74 \pm 1.04$ & $-.03 \pm .66$ & $-.87 \pm .65$ & c- $.29 \pm .94$ & $-.26 \pm .44$ & $-.49 \pm .88$ & $-.24 \pm .72$ \\
\hline Calm & $.59 \pm 1.06$ & $-.62 \pm .91$ & $.29 \pm 1.05$ & $-1.0 \pm 1.19$ & $-.29 \pm 1.63$ & $-.37 \pm 1.50$ & $.10 \pm .56$ & $-.24 \pm 2.17$ \\
\hline Surprise & $1.29 \pm 1.56$ & $.24 \pm 1.15$ & $.69 \pm 1.32$ & $-1.0 \pm 1.19$ & $.79 \pm 1.13$ & $-.74 \pm 1.15$ & $.29 \pm 1.48$ & $.13 \pm 1.12$ \\
\hline Fear & $.19 \pm .63$ & $.00 \pm .01$ & $.59 \pm .83$ & $.00 \pm .00$ & $1.00 \pm 1.04$ & $-.12 \pm .34$ & $-29 \pm 1.41$ & $-.62 \pm 1.40$ \\
\hline $\mathrm{Sad}$ & $.29 \pm 1.05$ & $-.49 \pm .75$ & $-.39 \pm .98$ & $-4.9 \pm 1.09$ & $1.19 \pm 1.02$ & $.13 \pm .98$ & $.49 \pm 1.50$ & $1.01 \pm 2.51$ \\
\hline Disgust & $-.19 \pm 1.21$ & $-.37 \pm 1.05$ & $-.19 \pm .62$ & $.49 \pm 1.18$ & $.00 \pm .00$ & $.26 \pm .45$ & $.79 \pm 1.02$ & -.26 .72 \\
\hline Interest & $1.01 \pm .81$ & $.62 \pm 1.18$ & $.49 \pm .70$ & $-1.11 \pm 2.0$ & $.19 \pm .78$ & $-.63 \pm .73$ & $-.29 \pm .94$ & $.12 \pm .63$ \\
\hline Anger & $-.11 \pm 1.19$ & $-.25 \pm .45$ & $.79 \pm 1.02$ & $.13 \pm .82$ & $.48 \pm .98$ & $.13 \pm .65$ & $1.39 \pm 1.44$ & $.37 \pm 1.50$ \\
\hline Peace & $.19 \pm 1.13$ & $.75 \pm 1.03$ & $-.10 \pm .87$ & $.00 \pm .00$ & $-.19 \pm 1.39$ & $-.49 \pm .52$ & $.29 \pm 1.24$ & $.49 \pm .75$ \\
\hline Joy & $.49 \pm .84$ & $1.01 \pm 1.19$ & $.01 \pm .93$ & $-.62 \pm .73$ & $-1.0 \pm .56$ & $-.24 \pm .46$ & $.69 \pm 1.05$ & $.24 \pm .90$ \\
\hline Comfort & $.71 \pm .93$ & $.74 \pm 1.03$ & $.49 \pm .84$ & $.00 \pm .52$ & $.49 \pm 1.07$ & $-.12 \pm .82$ & $.89 \pm .99$ & $1.12 \pm 1.24$ \\
\hline Hope & $.31 \pm .81$ & $.12 \pm .84$ & $.39 \pm .96$ & $.12 \pm .63$ & $-.19 \pm 1.13$ & $.12 \pm .64$ & $.29 \pm 1.05$ & $.87 \pm .66$ \\
\hline Thanksgiving & $.69 \pm 1.15$ & $1.24 \pm 1.38$ & $.69 \pm .81$ & $-.12 \pm .82$ & $.29 \pm .94$ & $-.02 \pm .53$ & $.39 \pm 1.14$ & $.74 \pm .70$ \\
\hline Wonderful & $1.79 \pm .91$ & $-.37 \pm .51$ & $.49 \pm 1.07$ & $.37 \pm 1.50$ & $1.01 \pm 1.14$ & $.74 \pm 1.27$ & $.39 \pm 1.32$ & $1.12 \pm 1.23$ \\
\hline Sadness & $-.21 \pm .78$ & $-.38 \pm .51$ & $.49 \pm 1.07$ & $.37 \pm 1.50$ & $1.01 \pm 1.14$ & $.74 \pm 1.27$ & $.79 \pm 1.02$ & $.87 \pm 2.22$ \\
\hline Sad & $-2.1 \pm .78$ & $-.37 \pm .51$ & $.11 \pm 1.44$ & $.50 \pm .92$ & $1.11 \pm 1.10$ & $.74 \pm 1.14$ & $.69 \pm 1.73$ & $.75 \pm .2 .74$ \\
\hline
\end{tabular}

Table 3

Descriptive Statistics for Each Period of Periodic Indicators

\begin{tabular}{|c|c|c|c|c|c|c|c|c|}
\hline \multirow{2}{*}{ Experience project } & \multicolumn{2}{|c|}{ Baseline $(\mathrm{M} \pm \mathrm{SD})$} & \multicolumn{2}{|c|}{ A condition $(\mathrm{M} \pm \mathrm{SD})$} & \multicolumn{2}{|c|}{$\mathrm{B}$ condition $(\mathrm{M} \pm \mathrm{SD})$} & \multicolumn{2}{|c|}{$\mathrm{C}$ condition $(\mathrm{M} \pm \mathrm{SD})$} \\
\hline & 2-3minutes & 3-4minutes & 2-3minutes & 3-4minutes & 2-3minutes & 3-4minutes & 2-3minutes & 3-4minutes \\
\hline Oxygen saturation & $96.51 \pm 44$ & $96.77 \pm 39$ & $96.66 \pm 27$ & $96.61 \pm 34$ & $96.57 \pm 52$ & $96.55 \pm 49$ & $96.55 \pm 40$ & $96.66 \pm 42$ \\
\hline Heart rate & $73.45 \pm 10.1$ & $74.8 \pm 13.3$ & $75.57 \pm 15.8$ & $75.45 \pm 11$ & $73.39 \pm 9.9$ & $72.63 \pm 8.9$ & $76.42 \pm 18$ & $76.73 \pm 9.6$ \\
\hline Skin electricity & $.67 \pm 36$ & $.66 \pm 39$ & $.68 \pm 37$ & $\pm 67 \pm 38$ & $.70 \pm 36$ & $.68 \pm 36$ & $.67 \pm 35$ & $.65 \pm 37$ \\
\hline Skin temperature & $.42 \pm 0.1$ & $.42 \pm 0.2$ & $.42 \pm 0.2$ & $.42 \pm 0.1$ & $.42 \pm 0.2$ & $.42 \pm 0.1$ & $.42 \pm 0.2$ & $.42 \pm 0.1$ \\
\hline Respiratory rate & $16.22 \pm 2.8$ & $16.05 \pm 2.6$ & $15.64 \pm 3.1$ & $16.11 \pm 3.3$ & $16.61 \pm 2.8$ & $16.19 \pm 3.2$ & $15.50 \pm 2.5$ & $15.60 \pm 2.9$ \\
\hline Respiratory rate & $-1.14 \pm 5.2$ & $-7.94 \pm 4.9$ & $-1.49 \pm 5.2$ & $-1.35 \pm 5.3$ & $-1.90 \pm 5.6$ & $-1.79 \pm 5.5$ & $-2.33 \pm 5.4$ & $-2.19 \pm 5.3$ \\
\hline
\end{tabular}




\section{Experimental Results and Analysis}

Difference of changes in subjective emotion experience. Table 2 shows the statistical results of changes in subjective emotional experience when subjects with or without ideological and political education saw different pictures. From the table, it can be seen that the 16 kinds of emotional experience all reached significant correlation, and there was no significant difference between the emotions of those who received and didn't receive education. On the other hand, there was a significant correlation between the experimental items and experimental materials, indicating that the four different pictures induced different emotions of the subjects with obvious differences. Those with and without ideological and political education had significant differences in the experience of many emotional words, and the subjects who did not receive ideological and political education featured low valence and arousal.

Autonomic Nervous Response Data and Analysis. Autonomic nervous and central nervous physiological responses were the main physiological responses measured in this experiment. Table 3 shows the basic data of the measured physiological indicators during the 2-3 minutes and 3-4 minutes.From the test data in the table, it can be seen that the six autonomic physiological indices induced by the four sets of pictures were not significantly different. However, previous studies have shown (Konopka, 2014) that when heart rate and skin temperature are stimulated by different emotions, there will be significant changes, and men and women show different changes if stimulated by different emotions. This may be because the absolute value of the physiological response was used in this paper, while previous tests adopted the relative value.

EEG Data and Analysis. For more accurate results, five kinds of brain waves, $\alpha, \beta, \theta, \delta$ and $\gamma$, were collected in this experiment, with a detailed analysis. Due to limited space, only $\theta$ and $\delta$ are introduced here.

By analyzing the $\delta$-wave at different time intervals, the main effect between $\delta$-waves and ideological and political education were not identified. However, based on the variance analysis on the maximum frequencies corresponding to the energy values of $\delta$-waves under different experimental materials, it can be found that $\delta$ wave in different brain regions had significant interaction with ideological and political education and gender, as shown in Figure 6.

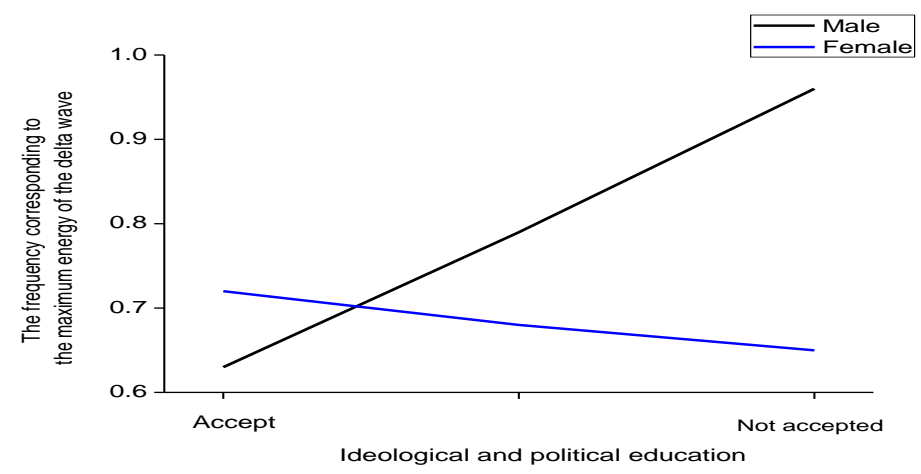

Figure 6. The interaction of ideological and political education types and gender on the frequency of the deltawave maximum energy in the central area. 
Through analysis of the descriptive statistics of each channel of $\theta$ wave energy, it was found that the energy of $\theta$ wave was mainly affected by the types of ideological and political education, and there was a significant interaction between ideological and political education and gender, as shown in Figure 7.

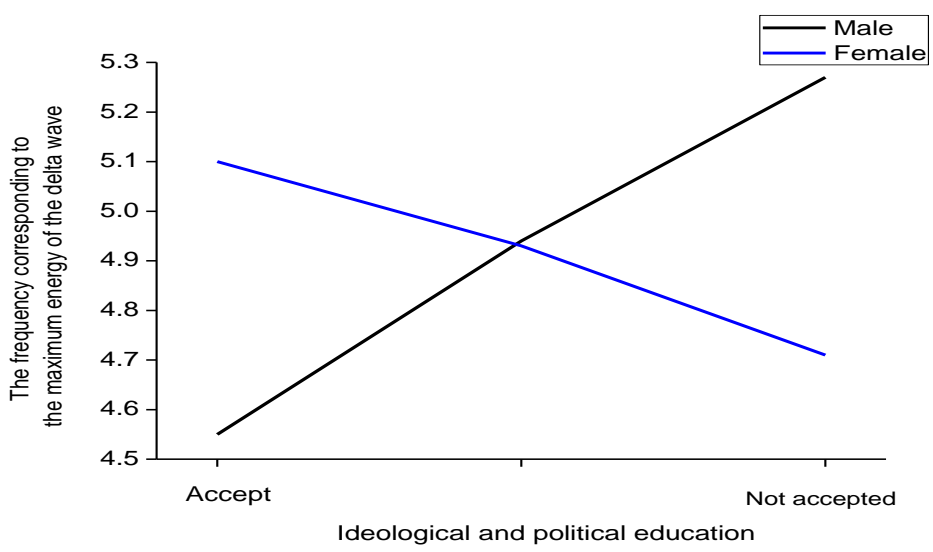

Figure 7. The interaction of ideological and political education types and gender on the frequency of maximum energy of theta wave in the central area.

Through the analysis of various brain waves, it can be concluded that the subjects receiving or not receiving ideological and political education have different performances in the maximum energy of brain waves, and it changes with time. Also, different experimental materials have different effects on different brain regions.

\section{Conclusion}

In this paper, four groups of different pictures were used to induce the emotions of the subjects and then the interaction between the ideological and political education and emotions of college students was researched through the neuroscience experiments. The specific conclusions are as follows:

(1) In terms of subjective emotional experience, subjects' subjective experience is affected by whether they have accepted ideological and political education, but is not highly related to the gender. And the subjects who have received ideological and political education present more positive emotion experiences, while those without such education are more likely to experience negative emotions.

(2) Different from the previous studies and the expectations of this paper, neither of the six autonomic physiological indicators induced by the four groups of pictures show the main effects of the experiments. 
(3) The activation of each brain area is related to the duration of stimulation. Through the analysis of the main effects of $\alpha, \beta, \theta, \delta$ waves in the brain regions and ideological and political education, it is shown that brainwaves are mainly affected by whether subjects accept ideological and political education, and those who have accepted ideological and political education show different manifestations of emotional experience in the maximum energy of brainwaves compared with the subjects who haven't received ideological and political education.

(4) Subjects who have received ideological and political education and those who have not received ideological and political education differ in emotional experience. The former tend to experience positive emotions that help subjects to accept ideological and political education.

\section{References}

Cabello, R., Navarro, B. B., Latorre, J. M., \& Fernándezberrocal, P. (2014). Ability of university-level education to prevent age-related decline in emotional intelligence. Frontiers in Aging Neuroscience, 6(11), 37. https://dx.doi.org/10.3389/fnagi.2014.00037

Cardoza, M. P. (2011). Neuroscience and simulation: an evolving theory of brain-based education. Clinical Simulation in Nursing, 7(6), e205-e208.

Francisca Pérez C, Anthea C., Alyson M., Antonia Q., Diego R., Javiera N., Camila V. (2018), Assessment of postpartum depression in a group of Chilean parents, 2018, Journal of Men's Health, 14(2), e56-e64; DOI: 10.22374/1875-6859.14.2.7

Gagen, E. A. (2015). Governing emotions: citizenship, neuroscience and the education of youth. Transactions of the Institute of British Geographers, 40(1), 140-152. https://dx.doi.org/10.1111/tran.12048

Gerard, O., Carthel, C., \& Coraluppi, S. (2016). Automatic detection and classification of beaked whale acoustic signals, Traitement Du Signal, 33(4), 73-94. https://doi.org/10.3166/TS.33.73-94

Goswami, U. (2006). Neuroscience and education: from research to practice?. Nature Reviews Neuroscience, 7(5), 406. https://dx.doi.org/10.1038/nrn1907

Hinton, C., Miyamoto, K., \& Della-Chiesa, B. (2010). Brain research, learning and emotions: implications for education research, policy and practice 1. European Journal of Education, 43(1), 87-103. https://dx.doi.org/10.1111/j.1465-3435.2007.00336.x

Kashihara, K. (2014). A brain-computer interface for potential non-verbal facial communication based on eeg signals related to specific emotions. Frontiers in Neuroscience, 8(5), 244. https://dx.doi.org/10.3389/fnins.2014.00244

Konopka, L. M. (2014). Neuroscience prospective on education. Croatian Medical Journal, 55(4), 428-430.

Liew, J. (2012). Effortful control, executive functions, and education: bringing self-regulatory and socialemotional competencies to the table. Child Development Perspectives, 6(2), 105-111. https://dx.doi.org/10.1111/j.1750-8606.2011.00196.x

Nadeau, R., Niemi, R. G., \& Amato, T. (1995). Emotions, issue importance, and political learning. American Journal of Political Science, 39(3), 558-574. https://doi.org/10.2307/2111644 
Panksepp, J. (1992). A critical role for "affective neuroscience" in resolving what is basic about basic emotions. Psychological Review, 99(3), 554-560.

Pekrun, R. (2006). The control-value theory of achievement emotions: assumptions, corollaries, and implications for educational research and practice. Educational Psychology Review, 18(4), 315-341. https://dx.doi.org/10.1007/s10648-006-9029-9

Robinson, K. (2013). The interrelationship of emotion and cognition when students undertake collaborative group work online: an interdisciplinary approach. Computers \& Education, 62(3), 298-307. https://doi.org/10.1016/j.compedu.2012.11.003

Rustichini, A. (2005). Neuroscience. Emotion and reason in making decisions. Science, 310(5754), 1624-1625. https://dx.doi.org/10.1126/science.1122179

Schutz, P. A., \& DeCuir, J. T. (2002). Inquiry on emotions in education. Educational Psychologist, 37(2), 125134. https://dx.doi.org/10.1207/S15326985EP3702_7

Seyong J., Wi-Young So (2017), The Effect of Short-Term Outdoor Taekwondo Training on the Concentration and Mood of Taekwondo Players Journal of Men's Health, 13(2), e67-e75; DOI: 10.22374/18756859.13.2.9

Trigwell, K. (2012). Relations between teachers' emotions in teaching and their approaches to teaching in higher education. Instructional Science, 40(3), 607-621. https://dx.doi.org/10.1007/s11251-011-9192-3

Yaacoub, T., Pistea, A.M., Youssef, R., Radoi, E., \& Burel, G. (2016). Compressed sampling of bandpass signals with finite rate of innovation Application to UWB channel estimation and indoor accurate localization. Traitement Du Signal, 33(4), 415-440. https://dx.doi.org/10.3166/TS.33.415-440

Zellner, M. (1998). Affective neuroscience: the foundations of human and animal emotions. American Journal of Psychiatry, 159(10), 1805. https://dx.doi.org/10.1080/15294145.2000.10773322

Zembylas, M. (2007). Emotional capital and education: theoretical insights from Bourdieu. British Journal of Educational Studies, 55(4), 443-463. https://dx.doi.org/10.1111/j.1467-8527.2007.00390.x 